\title{
General parenting styles are not strongly associated with fruit and vegetable intake and social-environmental correlates among 11 -year-old children in four countries in Europe
}

\author{
I De Bourdeaudhuij ${ }^{1, *}$, SJ te Velde ${ }^{2}, \mathrm{~L} \mathrm{Maes}^{3}, \mathrm{C}$ Pérez-Rodrigo ${ }^{4}, \mathrm{MDV}$ de Almeida ${ }^{5}$ and \\ J Brug ${ }^{2}$ \\ 'Department of Movement and Sport Sciences, Ghent University, Watersportlaan 2, B-9000 Ghent, Belgium: \\ ${ }^{2}$ EMGO Institute, VU University Medical Centre, Amsterdam, The Netherlands: ${ }^{3}$ Department of Public Health, \\ Ghent University, Ghent, Belgium: ${ }^{4}$ Community Nutrition Unit, Department of Public Health, Bilbao, Spain: \\ ${ }^{5}$ Faculty of Nutrition and Food Sciences, Porto University, Porto, Portugal
}

Submitted 18 December 2007: Accepted 2 May 2008: First published online 11 July 2008

\begin{abstract}
Objectives: To investigate whether fruit and vegetable (F\&V) intake in 11-year-olds, and social-environmental correlates of F\&V intake such as parental modelling and encouragement, family food rules and home availability, differ according to general parenting styles in Belgium, The Netherlands, Portugal and Spain.

Design: Cross-sectional study.

Setting: Primary schools in four countries.

Subjects: Pupils and one of their parents completed questionnaires to measure F\&V intake, related social-environmental correlates and general parenting styles. The sample size was 4555 (49.3\% boys); 1180 for Belgium, 883 for The Netherlands, 1515 for Portugal and 977 for Spain. Parenting styles were divided into authoritative, authoritarian, indulgent and neglectful.

Results: No differences were found in F\&V intake across parenting styles and only very few significant differences in social-environmental correlates. The authoritarian (more parental encouragement and more demands to eat fruit) and the authoritative (more availability of fruit and vegetables) parenting styles resulted in more favourable correlates.

Conclusion: Despite earlier studies suggesting that general parenting styles are associated with health behaviours in children, the present study suggests that this association is weak to non-existent for $\mathrm{F} \& \mathrm{~V}$ intakes in four different European countries.
\end{abstract}

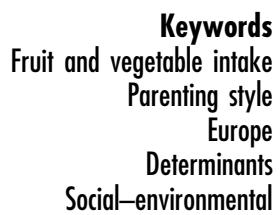

Recent research on fruit and vegetable (F\&V) intakes among 11-year-olds in nine European countries revealed that intakes were below recommended levels in all countries $^{(1)}$. Recent reviews suggest that parental and family social-environmental factors such as family socioeconomic status, parental modelling and home availability may be relevant mediators of intakes and should therefore be taken into account in intervention development ${ }^{(2-4)}$. Other studies on potential determinants of health behaviour in children and adolescents suggested that general parenting styles are also important ${ }^{(5-7)}$.

Parental style refers to the general patterns of parenting relevant for a broad range of topics and captures two important elements: parental involvement and parental strictness ${ }^{(8)}$. In general, authoritative parenting characterized by high parental strictness and involvement has been found to be associated with more healthful behaviour in children ${ }^{(9,10)}$. Despite the current consensus on the importance of family involvement in eating habits in children and adolescents, very few studies have investigated these general parenting styles in relation to nutrition in general or F\&V intake in particular. In the review of Rasmussen $e t$ al. $^{(2)}$ six papers were identified investigating $\mathrm{F} \& \mathrm{~V}$ intake and some aspects of general parenting styles. While three papers showed no significant relationships ${ }^{(11-13)}$, some evidence was found for highest F\&V intake levels in authoritative parents (or mothers), who combined high responsiveness with high demand in the interaction with their children ${ }^{(7,14,15)}$. The authoritative parenting style was also found to be superior to other styles in studies on social competence, psychosocial functioning, problem behaviour and substance abuse ${ }^{(9,10)}$. If this is also true for eating behaviours such as F\&V consumption in children, this would open 
possibilities for designing broader intervention strategies, targeting different aspects of children's behaviour and functioning at a time by focusing on general parenting competences.

Baumrind's ${ }^{(9,10)}$ parenting style concept was developed and used initially in the USA. As mentioned before, some European studies also used these general parenting styles in their research. However, several authors have drawn attention to cultural or ethnic differences in parenting style studies which may be due to differences in social context, parenting practices, or the cultural meaning of specific dimensions of parenting style ${ }^{(16,17)}$. To date it is unclear whether parenting in European countries, and especially the assessment of general parenting styles, is similar or different from that in the USA. More specifically, cultural differences in the meaning of specific dimensions of parenting styles may exist even within different countries in Europe. As a consequence, interaction between parenting styles and country has to be taken into account.

The aim of the present study was to investigate whether F\&V intake in 11-year-olds, and social-environmental correlates of $\mathrm{F} \& \mathrm{~V}$ intake such as modelling, encouragement, family food rules and home availability, differ according to general parenting styles and whether this difference is dependent on country (Belgium, The Netherlands, Portugal and Spain).

\section{Methods}

\section{Procedure and participants}

Data were derived from the cross-sectional study of the Pro Children project ${ }^{(18)}$. Data were collected during October-December 2003 in nine European countries among children and their parents. Schools constituted the sampling unit, and from each country random samples of at least twenty schools and a minimum of 1300 11-year-old eligible children were recruited. Four of the nine countries agreed to include an optional measure on parenting styles in the parent questionnaire: Belgium, The Netherlands, Portugal and Spain. Pupils completed a questionnaire in the classroom and took a questionnaire home to be completed by one of their parents. The sample sizes were 1180 for Belgium, 883 for The Netherlands, 1515 for Portugal and 977 for Spain (total sample size 4555; 49.3\% boys). Parental response rates ranged from $67 \cdot 8 \%$ in The Netherlands to $83.4 \%$ in Portugal ${ }^{(19)}$. Background information on the sample is reported in Table 1.

Ethical approval was obtained from all relevant ethics committees in all countries and written informed consent forms were signed by parents of all participating children. A detailed description of the Pro Children project, including the sampling and data collection procedure, is given elsewhere ${ }^{(1,18)}$.

\section{Measures}

A self-report questionnaire for the children was developed and pre-tested to measure fruit intake and vegetable intake, and possible correlates, based on a social-ecological framework, a literature review and interviews with children, parents and school staff ${ }^{(20,21)}$.

Usual intakes of fruit and vegetables were assessed using an FFQ. Children were asked how often they usually eat fresh fruit, salad or grated vegetables, other raw vegetables and cooked vegetables. Response categories were: (i) never; (ii) less than one day per week; (iii) one day per week; (iv) 2-4 days per week; (v) 5-6 days per week; (vi) every day, once daily; (vii) every day, twice daily; and (viii) every day, more than twice daily. A separate study was executed to test the reliability and validity of these intake measures in six countries. Results showed good test-retest reliability (Spearman $r$ from $0 \cdot 45$

Table 1 Background characteristics (\%) of the samples in the four countries: data derived from the cross-sectional study of the Pro Children project, October-December 2003

\begin{tabular}{|c|c|c|c|c|}
\hline & Belgium & Netherlands & Portugal & Spain \\
\hline \multicolumn{5}{|l|}{ Child born in } \\
\hline 1990 & $1 \cdot 3$ & $2 \cdot 9$ & 0 & $0 \cdot 4$ \\
\hline 1991 & $14 \cdot 4$ & $37 \cdot 8$ & $18 \cdot 6$ & $12 \cdot 0$ \\
\hline 1992 & $83 \cdot 2$ & $58 \cdot 8$ & $81 \cdot 4$ & $87 \cdot 4$ \\
\hline 1993 & $1 \cdot 0$ & 0.5 & 0 & 0.2 \\
\hline \multicolumn{5}{|l|}{ Gender of child } \\
\hline Boy & $54 \cdot 2$ & $46 \cdot 2$ & $47 \cdot 4$ & $53 \cdot 7$ \\
\hline \multicolumn{5}{|l|}{ Family education level } \\
\hline Level 1 (lowest) & $3 \cdot 3$ & $3 \cdot 2$ & $50 \cdot 5$ & $14 \cdot 6$ \\
\hline Level 2 & $13 \cdot 8$ & $7 \cdot 8$ & $19 \cdot 6$ & $42 \cdot 5$ \\
\hline Level 3 & $39 \cdot 5$ & $21 \cdot 9$ & $16 \cdot 7$ & $15 \cdot 5$ \\
\hline Level 4 (highest) & 43.3 & $67 \cdot 1$ & $13 \cdot 2$ & $27 \cdot 5$ \\
\hline \multicolumn{5}{|l|}{ Child born in this country? } \\
\hline No & $4 \cdot 6$ & $5 \cdot 3$ & $5 \cdot 3$ & $9 \cdot 5$ \\
\hline \multicolumn{5}{|l|}{ Mother born in this country? } \\
\hline No & $11 \cdot 4$ & $12 \cdot 0$ & $10 \cdot 2$ & $11 \cdot 5$ \\
\hline \multicolumn{5}{|l|}{ Parent questionnaire filled in by } \\
\hline Mother/stepmother/female guardian & $87 \cdot 4$ & $88 \cdot 1$ & $82 \cdot 7$ & $89 \cdot 6$ \\
\hline
\end{tabular}




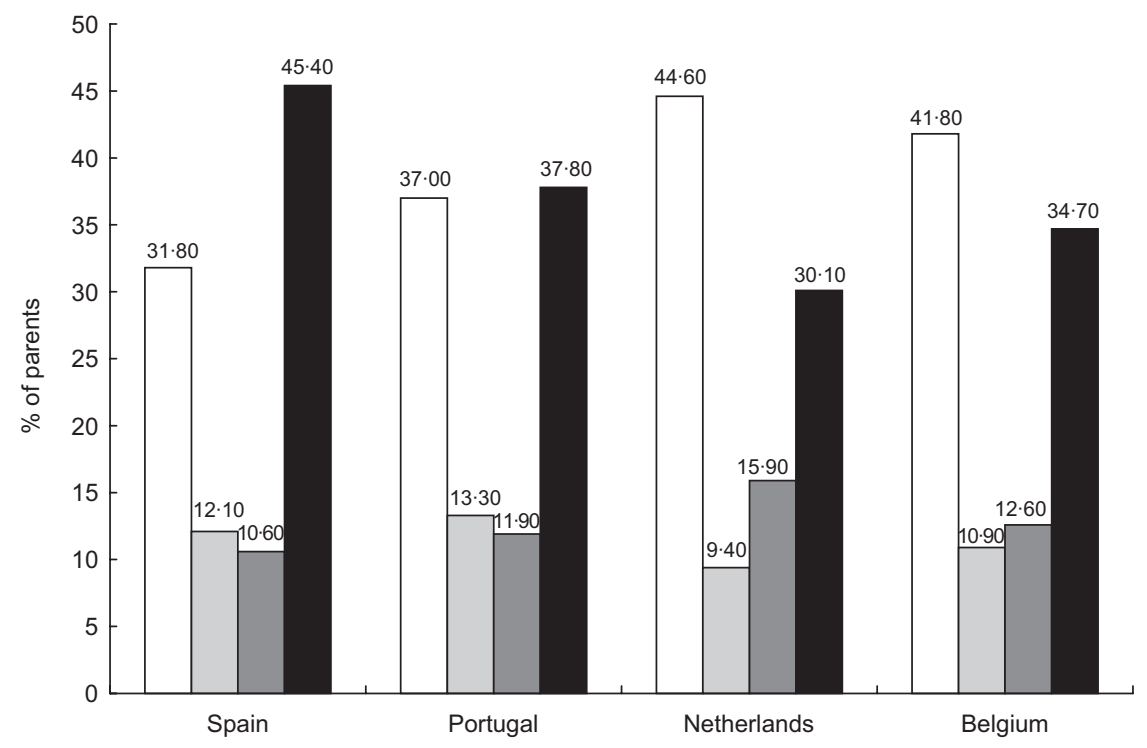

Fig. 1 Percentages of parents in the four categories of parenting styles ( $\square$, authoritative; $\square$, authoritarian; $\square$, indulgent; $\square$, neglectful) in the four countries. Data were derived from the cross-sectional study of the Pro Children project, October-December 2003

to $0 \cdot 77)$ and adequate validity comparing the foodfrequency questions with $7 \mathrm{~d}$ food records (Spearman $r$ from 0.38 to 0.53 ). Frequencies were re-coded into portions per day ${ }^{(22)}$.

The child questionnaire also included personal factors, social factors and environmental factors as potential correlates of fruit intake and vegetable intake. These constructs were analogous for fruit and vegetable intakes. Six social-environmental constructs were included here for their relevance to parenting styles: (i) modelling (mother/ father/best friend eats fruit/vegetables); (ii) active parental encouragement (mother/father encourages); (iii) family rules - demands (parents demand to eat fruit/ vegetables); (iv) family rules - allowances (allowed to eat as much fruit/vegetables as you like); (v) parental facilitation (cut fruit/vegetables for child); and (vi) home availability (different fruits/vegetables, fruit/vegetables that you like, if you like it will be bought). These constructs were assessed with one to three items, and for each construct a composite score was calculated as the mean of the relevant item scores. Responses were given on 5 -point scales ranging from -2 (fully disagree/never) to +2 (fully agree/always). An overview of the items, constructs and scaling is given elsewhere ${ }^{(20,23)}$. A separate study in five countries showed sufficient internal consistency for composite scores (values of $\alpha$ between 0.65 and $0 \cdot 89$; not computed for family rules as they consisted of only one item), good to very good test-retest reliability (most intra-class correlations $>0 \cdot 60$; all $>0.50$ ) and moderate predictive validity (Spearman $r$ ranging from 0.05 to 0.38 for social and environmental factors) compared with other studies ${ }^{(20)}$.

Parenting styles were included in the parent questionnaire based on the Steinberg instrument. This instrument is considered one of the best measurement tools available to measure parenting styles and has been used extensively in the USA ${ }^{(24)}$. Four parenting styles were computed based on two parenting style dimensions: strictness and involvement ${ }^{(24-26)}$. The involvement and strictness scales included nine and seven items respectively, and parents answered on a 5-point scale ranging from completely untrue to completely true. Internal consistencies were $\alpha=0.76$ for the involvement scale and $\alpha=0.75$ for the strictness scale. Based on the median value of both scales, parents were categorized as authoritative (high on involvement and high on strictness), authoritarian (high on strictness, low on involvement), indulgent (high on involvement, low on strictness) or neglectful (low on involvement and low on strictness). Figure 1 shows the distribution of the four parenting styles over the four participating countries.

Family educational level was assessed in the parents' questionnaire. The highest level of education reported by either parent was used as an estimate of family educational level. In the analyses this variable was entered as a categorical variable with four categories based on years of education.

All protocols and questionnaires of the Pro Children study can be accessed at www.prochildren.org.

\section{Statistical analyses}

Two-way ANOVA were used to investigate whether fruit intake, vegetable intake and social-environmental correlates of fruit and vegetable intakes differed between the four parenting styles and between the four countries. For each analysis, the main effect of parenting style, the main effect of country and the interaction between both are reported. Differences between the four countries are 
reported only for reasons of completeness, but are not the main research question of the present work. Differences between countries were reported previously ${ }^{(1,19,27)}$.

Post hoc tests were used to detail specific group differences and are reported in the text. All ANOVA were controlled for gender, age and family education level. Although the pupils were all recruited from the same grade, some age variability was observed (range 9-12 years) arguing for the inclusion of age as a covariate. Observed mean values and $F$ statistics are reported in the tables. The significance level was set at $P<0 \cdot 01$ to adjust for multiple statistical testing.

\section{Results}

Two-way ANOVA showed predominantly significant differences in fruit intake and in social-environmental correlates between the four countries. Highest levels of fruit intake were found in Portugal $(P<0 \cdot 001)$, followed by Spain $(P<0 \cdot 001)$, compared with lower levels in Belgium and The Netherlands (Table 2). Social-environmental correlates reflected the same trend. More modelling, parental encouragement, demand and home availability of fruit were found in Portugal and Spain than in Belgium and The Netherlands $(P<0 \cdot 001)$. Differences between parenting styles were not significant for fruit intake, but were significant for active parental encouragement, demand family rule and home availability of fruit. Children of parents with an authoritarian parenting style reported more active parental encouragement and more demands to eat fruit compared with children of parents with an indulgent or neglectful parenting style $(P<0 \cdot 01)$. In addition, children of parents with an authoritative parenting style reported more home availability of fruit than children of parents with a neglectful style $(P<0 \cdot 001)$. The significant interaction effect for modelling showed that children of parents with an indulgent style reported most modelling of

Table 2 Differences in fruit intake and social-environmental correlates of fruit intake between parenting style groups and the four countries (results of two-way ANOVA): data derived from the cross-sectional study of the Pro Children project, October-December 2003

\begin{tabular}{|c|c|c|c|c|c|c|c|}
\hline & Authoritative & Authoritarian & Indulgent & Neglectful & $\begin{array}{c}\text { Main effect: } \\
\text { country ( } F \text { value })\end{array}$ & $\begin{array}{l}\text { Main effect: parenting } \\
\text { style ( } F \text { value })\end{array}$ & $\begin{array}{l}\text { Interaction effect } \\
\quad(F \text { value })\end{array}$ \\
\hline \multicolumn{8}{|c|}{ Fruit intake (portions/d) } \\
\hline Belgium & 0.85 & 0.97 & 0.77 & 0.92 & & & \\
\hline Netherlands & $0 \cdot 87$ & 1.03 & $0 \cdot 88$ & 0.89 & & & \\
\hline Portugal & $1 \cdot 24$ & $1 \cdot 20$ & $1 \cdot 29$ & $1 \cdot 10$ & & & \\
\hline Spain & 0.99 & $1 \cdot 04$ & $1 \cdot 07$ & $1 \cdot 02$ & $44 \cdot 02^{\star *}$ & $1 \cdot 32$ & $1 \cdot 79$ \\
\hline \multicolumn{8}{|c|}{ Social-environmental correlates (range -2 to +2 ) } \\
\hline Modelling & & & & & & & \\
\hline Belgium & 0.43 & 0.48 & $0 \cdot 39$ & 0.40 & & & \\
\hline Netherlands & $0 \cdot 78$ & $0 \cdot 86$ & 0.52 & $0 \cdot 75$ & & & \\
\hline Portugal & $1 \cdot 13$ & $1 \cdot 00$ & $1 \cdot 24$ & $1 \cdot 11$ & & & \\
\hline Spain & $1 \cdot 00$ & $1 \cdot 00$ & 0.99 & 0.98 & $137 \cdot 02^{\star \star}$ & $0 \cdot 68$ & $2 \cdot 65^{\star}$ \\
\hline \multicolumn{8}{|l|}{$\begin{array}{l}\text { Active parental } \\
\text { encouragement }\end{array}$} \\
\hline Belgium & 0.32 & 0.43 & $0 \cdot 11$ & $0 \cdot 27$ & & & \\
\hline Netherlands & $0 \cdot 30$ & 0.27 & -0.06 & 0.08 & & & \\
\hline Portugal & $1 \cdot 20$ & $1 \cdot 21$ & $1 \cdot 29$ & 1.09 & & & \\
\hline Spain & $1 \cdot 10$ & $1 \cdot 26$ & $1 \cdot 08$ & $1 \cdot 03$ & $180 \cdot 06^{\star \star}$ & $4 \cdot 66^{*}$ & $1 \cdot 51$ \\
\hline \multicolumn{8}{|c|}{ Demand family rule } \\
\hline Belgium & -0.22 & 0.07 & -0.38 & -0.20 & & & \\
\hline Netherlands & 0.55 & 0.64 & 0.20 & 0.33 & & & \\
\hline Portugal & $1 \cdot 24$ & $1 \cdot 14$ & $1 \cdot 29$ & 1.09 & & & \\
\hline Spain & $0 \cdot 86$ & 0.89 & $0 \cdot 77$ & $0 \cdot 72$ & $235 \cdot 84^{\star \star}$ & $5 \cdot 15^{\star}$ & 1.99 \\
\hline \multicolumn{8}{|l|}{ Allow family rule } \\
\hline Belgium & 1.55 & $1 \cdot 51$ & 1.55 & $1 \cdot 43$ & & & \\
\hline Netherlands & $1 \cdot 47$ & $1 \cdot 42$ & $1 \cdot 43$ & $1 \cdot 39$ & & & \\
\hline Portugal & 1.58 & $1 \cdot 58$ & 1.59 & $1 \cdot 51$ & & & \\
\hline Spain & $1 \cdot 42$ & $1 \cdot 26$ & $1 \cdot 44$ & $1 \cdot 40$ & $7 \cdot 76^{\star *}$ & $1 \cdot 52$ & 0.50 \\
\hline \multicolumn{8}{|c|}{ Family facilitation } \\
\hline Belgium & -0.04 & 0.02 & $-0 \cdot 18$ & $-0 \cdot 13$ & & & \\
\hline Netherlands & -0.03 & -0.04 & -0.06 & $-0 \cdot 17$ & & & \\
\hline Portugal & 0.05 & $-0 \cdot 12$ & 0.04 & -0.09 & & & \\
\hline Spain & $-0 \cdot 14$ & -0.24 & -0.13 & -0.23 & $2 \cdot 75$ & $1 \cdot 85$ & 0.46 \\
\hline \multicolumn{8}{|c|}{ Availability at home } \\
\hline Belgium & $1 \cdot 30$ & $1 \cdot 26$ & $1 \cdot 15$ & $1 \cdot 18$ & & & \\
\hline Netherlands & $1 \cdot 28$ & $1 \cdot 23$ & $1 \cdot 27$ & $1 \cdot 15$ & & & \\
\hline Portugal & $1 \cdot 56$ & $1 \cdot 46$ & 1.53 & $1 \cdot 45$ & & & \\
\hline Spain & $1 \cdot 48$ & 1.46 & $1 \cdot 47$ & $1 \cdot 48$ & $51 \cdot 54^{\star *}$ & $4 \cdot 93^{*}$ & $1 \cdot 18$ \\
\hline
\end{tabular}

All analyses were controlled for gender, age and family education level.

Significance of effect: ${ }^{\star} P<0 \cdot 01,{ }^{\star \star} P<0.001$. 
Table 3 Differences in vegetable intake and social-environmental correlates of vegetable intake between parenting style groups and the four countries (results of two-way ANOVA): data derived from the cross-sectional study of the Pro Children project, October-December 2003

\begin{tabular}{|c|c|c|c|c|c|c|c|}
\hline & Authoritative & Authoritarian & Indulgent & Neglectful & $\begin{array}{c}\text { Main effect: } \\
\text { country ( } F \text { value) }\end{array}$ & $\begin{array}{l}\text { Main effect: parenting } \\
\text { style ( } F \text { value) }\end{array}$ & $\begin{array}{c}\text { Interaction effect } \\
\quad(F \text { value })\end{array}$ \\
\hline \multicolumn{8}{|c|}{ Vegetable intake (portions/d) } \\
\hline Belgium & $1 \cdot 30$ & 1.45 & $1 \cdot 33$ & $1 \cdot 35$ & & & \\
\hline Netherlands & $1 \cdot 34$ & 1.50 & 1.37 & $1 \cdot 26$ & & & \\
\hline Portugal & $1 \cdot 41$ & $1 \cdot 36$ & $1 \cdot 48$ & $1 \cdot 26$ & & & \\
\hline Spain & $1 \cdot 00$ & 0.91 & 0.98 & 0.90 & $31 \cdot 92^{\star *}$ & $1 \cdot 93$ & 0.99 \\
\hline \multicolumn{8}{|c|}{ Social-environmental correlates (range -2 to +2 ) } \\
\hline Modelling & & & & & & & \\
\hline Belgium & $0 \cdot 70$ & 0.68 & $0 \cdot 61$ & 0.69 & & & \\
\hline Netherlands & 0.96 & $1 \cdot 12$ & $0 \cdot 89$ & 0.99 & & & \\
\hline Portugal & 0.83 & 0.78 & 0.96 & 0.79 & & & \\
\hline Spain & 0.45 & 0.40 & 0.49 & 0.45 & $52 \cdot 82^{\star \star}$ & $0 \cdot 14$ & $1 \cdot 30$ \\
\hline \multicolumn{8}{|l|}{$\begin{array}{l}\text { Active parental } \\
\text { encouraqement }\end{array}$} \\
\hline Belgium & 0.55 & 0.56 & 0.24 & 0.41 & & & \\
\hline Netherlands & 0.41 & 0.69 & $0 \cdot 30$ & 0.47 & & & \\
\hline Portugal & 0.96 & 0.91 & 0.97 & $0 \cdot 81$ & & & \\
\hline Spain & 0.67 & 0.68 & 0.68 & 0.58 & $37 \cdot 89^{\star *}$ & $2 \cdot 44$ & $1 \cdot 40$ \\
\hline \multicolumn{8}{|c|}{ Demand family rule } \\
\hline Belgium & $0 \cdot 22$ & 0.38 & 0.05 & $0 \cdot 16$ & & & \\
\hline Netherlands & 0.79 & 0.99 & 0.65 & 0.82 & & & \\
\hline Portugal & 0.99 & $0 \cdot 80$ & 1.05 & $0 \cdot 77$ & & & \\
\hline Spain & 0.42 & 0.43 & 0.35 & 0.38 & $76 \cdot 35^{\star \star}$ & $1 \cdot 62$ & $1 \cdot 76$ \\
\hline \multicolumn{8}{|l|}{ Allow family rule } \\
\hline Belgium & $1 \cdot 24$ & $1 \cdot 39$ & $1 \cdot 22$ & $1 \cdot 28$ & & & \\
\hline Netherlands & $1 \cdot 21$ & $1 \cdot 33$ & $1 \cdot 35$ & $1 \cdot 26$ & & & \\
\hline Portugal & $1 \cdot 30$ & $1 \cdot 21$ & $1 \cdot 36$ & $1 \cdot 14$ & & & \\
\hline Spain & $1 \cdot 20$ & 0.89 & 1.04 & $1 \cdot 10$ & $6 \cdot 83^{\star *}$ & 0.28 & $1 \cdot 84$ \\
\hline \multicolumn{8}{|c|}{ Family facilitation } \\
\hline Belgium & -0.91 & -0.65 & -0.75 & -0.84 & & & \\
\hline Netherlands & -0.91 & -0.81 & $-0 \cdot 81$ & -0.89 & & & \\
\hline Portugal & $0 \cdot 36$ & $0 \cdot 34$ & $0 \cdot 62$ & 0.33 & & & \\
\hline Spain & -0.76 & -0.93 & -0.95 & -0.93 & $188 \cdot 63^{\star *}$ & 1.43 & $1 \cdot 45$ \\
\hline \multicolumn{8}{|c|}{ Availability at home } \\
\hline Belgium & 0.87 & 0.94 & $0 \cdot 80$ & 0.79 & & & \\
\hline Netherlands & 0.90 & 0.83 & 0.94 & 0.87 & & & \\
\hline Portugal & $1 \cdot 32$ & $1 \cdot 18$ & $1 \cdot 29$ & $1 \cdot 08$ & & & \\
\hline Spain & $1 \cdot 12$ & 1.02 & 1.03 & 1.07 & $40 \cdot 61^{\star *}$ & $3 \cdot 45^{\star}$ & $1 \cdot 68$ \\
\hline
\end{tabular}

All analyses were controlled for gender, age and family education level. Significance of effect: ${ }^{\star} P<0.01,{ }^{\star \star} P<0.001$.

fruit intake in Portugal, while in Belgium and The Netherlands, most modelling of fruit intake was reported by children of parents with an authoritarian style.

Table 3 shows that significance differences were also found between countries for vegetable intake and related correlates. Children in Portugal reported higher vegetable intake $(P<0 \cdot 001)$, those in Spain lower intake $(P<0 \cdot 001)$. Children in Portugal also reported most parental encouragement to eat vegetables, demands to eat vegetables, facilitation and home availability of vegetables, while children in Portugal and The Netherlands reported most modelling (all $P<0 \cdot 001$ ). Table 3 shows that no differences in vegetable intake related to parenting styles were found. Along the same line, very few differences across parenting styles were found in socialenvironmental correlates related to vegetable intake. Only for home availability of vegetables was a significant difference across parenting styles found. Children of parents with an authoritative parenting style reported more availability compared with children of parents with a neglectful style $(P=0 \cdot 01)$.

\section{Discussion}

No evidence was found in the present study for consistent differences in F\&V intakes or social-environmental correlates according to parenting style. Results showed no differences in $F \& V$ intake across parenting styles and only very few significant differences in social-environmental correlates.

The authoritarian (more parental encouragement and more demands to eat fruit) and the authoritative (more availability of fruit and vegetables) parenting styles resulted in more favourable correlates. Previous studies have already shown highest F\&V intake levels in authoritative parents (or mothers), who combined high responsiveness with high demand in the interaction with their children ${ }^{(7,14,15)}$. The authoritative parenting style was also found to be 
superior to other styles in studies on social competence, psychosocial functioning, problem behaviour and substance abuse $^{(9,10)}$. In contrast, a positive effect of an authoritarian parenting style was not expected in the present study. However, it is possible that authoritarian parenting, which goes together with encouraging, obliging or demanding that children eat fruit every day, may have a positive effect on fruit intake. Previous studies also showed that less permissiveness, more food rules and more restrictiveness were related to less fat, sweets, snacks and soft drinks and more healthy food choices in adolescents ${ }^{(4,13,28)}$. However, the results in the present study are very weak as parenting styles did not seem to affect the intake of F\&V and had a relationship with only some of the social-environmental correlates.

The present study showed clear differences between the four countries in the percentages of parents in the different parenting style categories. Cultural differences could be assumed between both southern European countries and both central European countries. In Portugal and Spain, higher percentages of parents were categorized within the neglectful parenting style. In Belgium and The Netherlands, highest percentages were found for the authoritative parenting style. Because of these differences the country was included as a factor in the analyses. However, almost no interaction effects were found. Several authors have already drawn attention to cultural or ethnic differences in parenting style studies which may be due to differences in social context, parenting practices, or the cultural meaning of specific dimensions of parenting style ${ }^{(16,17)}$.

The present study indicated that general parenting styles are of low relevance for $\mathrm{F} \& \mathrm{~V}$ intake. Other studies, including the Pro Children study, indicated that more specific diet and nutrition-related parenting practices are of greater importance in promoting healthful eating habits among youth ${ }^{(27)}$. However, Kremers et al. ${ }^{(7)}$ did find that adolescents who were raised in authoritative homes showed the healthiest behaviour as well as cognitions. A major difference with the study by Kremers et $a l .{ }^{(7)}$ is that the adolescents themselves completed the parenting questions in their study. Previous studies have shown that there are perception differences in the general picture adolescents and their parents have about the functioning of their families. Adolescents were found to report less emotional bonding, a less open and accepting relationship between parents and children, and more decisionmaking power and flexibility in rules, roles and power structure, in comparison with their parents ${ }^{(13,28,29)}$.

Significant differences in F\&V intake levels and in related social-environmental correlates were found between the four countries. These differences were beyond the scope of the present manuscript and were reported previously ${ }^{(1,19,27)}$. The present analyses additionally showed that these country differences in intake and correlates were not related to parenting styles.
Important strengths of the study are its large international sample and the use of a standardized, validated instrument to measure fruit intake and vegetable intake and their potential psychosocial and physical environmental correlates across diverse food-related cultural settings. Country samples are representative, total sample size is large and we obtained a high participation rate.

A weakness of the study is its cross-sectional nature, neither allowing prediction nor conclusions about directionality. In addition, the parenting style concept presumes only a unidirectional influence of parents on their children. Previous research, however, suggests that parents believe they are reactive rather than prescriptive in terms of their children's feeding practices ${ }^{(30)}$. More general, recent family research reacts upon this unidirectional paradigm and tries to disentangle the mutual and continuous influence of each party within the parent-child relationship $^{(31)}$. It would be worthwhile to also include the influence children exert on parents' parenting styles and practices in future longitudinal studies on health behaviours. A second weakness is the lack of clarity about the way in which parents in different countries and in different cultures complete or understand the parenting style questionnaires. In southern European countries, social norms do not prescribe parents' responsiveness as strongly as in central European countries. In the Nordic countries, the parenting style questionnaire had to be removed from the final parent questionnaire in the Pro Children study, as the pre-test showed that parents were reluctant to complete the questionnaire. Focus groups with parents in Norway, Sweden and Denmark revealed that cultural norms put high pressure on responsiveness to children and 'good parenting' in general, which makes the parenting questionnaire highly sensitive to complete.

In conclusion, the present study showed no support for the hypothesis that authoritative parenting is related to more $\mathrm{F} \& \mathrm{~V}$ intake or is related to more favourable correlates of $\mathrm{F} \& \mathrm{~V}$ intake in 11-year-olds. In general, no differences in $\mathrm{F} \& \mathrm{~V}$ intake and very few in related correlates were found across parenting styles, suggesting that focusing on general parenting will not be sufficient or adequate to change F\&V intake levels or related correlates. More specific food-related factors were found to be stronger determinants of F\&V intake in the Pro Children study ${ }^{(27)}$. This means that an intervention strategy focusing on increasing knowledge of the national recommendations, positive self-efficacy, positive liking and preference, parental modelling and demand, and bringing fruit to school would be more promising than focusing on general parenting styles.

\section{Acknowledgements}

The project 'Promoting and Sustaining Health through Increased Vegetable and Fruit Consumption among European Schoolchildren' (Pro Children) is funded under 
the Fifth Framework Programme of the European Commission, Thematic Programme 'Quality of Life and Management of Living Resources', Key Action 'Food, Nutrition and Health' (QLK1-CT-2001-00547). The Pro Children consortium consists of the following partners: Knut-Inge Klepp (Coordinator), Department of Nutrition, Faculty of Medicine, University of Oslo, Norway; Carmen PérezRodrigo, Unidad de Nutricion Comunitaria, Bilbao, Spain; Inga Thorsdottir, Unit for Nutrition Research, Landspitali University Hospital, Reykjavik, Iceland; Pernille Due, Department of Social Medicine, University of Copenhagen, Denmark; Maria Daniel Vaz de Almeida, Faculdade de Ciências da Nutrição e Alimentação da Universidade do Porto, Portugal; Ibrahim Elmadfa, Institute of Nutrition, University of Vienna, Austria; Jóhanna Haraldsdóttir, Research Department of Human Nutrition, Royal Veterinary and Agricultural University, Copenhagen, Denmark; Johannes Brug, Erasmus Medical Center Rotterdam, Department of Public Health, The Netherlands; Michael Sjöström and Agneta Yngve, Unit for Preventive Nutrition, Karolinska Institutet, Stockholm, Sweden; Ilse De Bourdeaudhuij, Department of Movement and Sport Sciences, Ghent University, Belgium. There is no conflict of interest for any of the authors of this manuscript. All authors contributed in setting up the study, data gathering, analyses, writing (parts of) the manuscript, and gave comments.

\section{References}

1. Yngve A, Wolf AM, Poortvliet E et al. (2005) Fruit and vegetable intake in a sample of 11 year old school-children in 9 European countries: The Pro Children Cross-sectional Survey. Ann Nutr Metab 49, 236-245.

2. Rasmussen M, Krølner R, Klepp KI, Lytle L, Brug J, Bere E \& Due P (2006) Determinants of fruit and vegetable consumption among children and adolescents: a review of the literature. Part I: quantitative studies. Int J Behav Nutr Phys Act 3, 22.

3. Blanchette L \& Brug J (2005) Determinants of fruit and vegetable consumption among 6-12-year-old children and effective interventions to increase consumption. J Hum Nutr Diet 18, 431-443.

4. Van Der Horst K, Kremers S, Ferreira I, Singh A, Oenema A \& Brug J (2007) Perceived parenting style and practices and the consumption of sugar-sweetened beverages by adolescents. Health Educ Res 22, 295-304.

5. Hughes SO, Power TG, Fisher JO, Mueller S \& Nicklas TA (2005) Revisiting a neglected construct: parenting styles in a child-feeding context. Appetite 44, 83-92.

6. Birch LL \& Fisher JO (1998) Development of eating behaviours among children and adolescents. Pediatrics 101, 539-549.

7. Kremers S, Brug J, de Vries H \& Engels R (2003) Parenting style and adolescent fruit consumption. Appetite $\mathbf{4 1}$, 43-50.

8. Maccoby EE \& Martin JA (1983) Socialization in the context of the family: parent-child interaction. In Handbook of Child Psychology, 4th ed. vol. IV: Socialization, Personality and Social Development, pp. 1-101 [PH Mussen and EM Hetherington, editors]. New York: John Wiley and Sons.
9. Baumrind D (1991) Effective parenting during the early adolescent transition. In Advances in Family Research, pp. 111-163 [PE Cowan and EM Hetherington, editors]. New York: John Wiley and Sons.

10. Baumrind D (1991) The influence of parenting style on adolescent competence and substance use. J Early Adolesc 11, 56-95.

11. Lien N, Jacobs DR \& Klepp KI (2002) Exploring predictors of eating behaviour among adolescents by gender and socioeconomic status. Public Health Nutr 5, 671-681.

12. Young EM, Fors SW, Fasha E \& Hayes DM (2004) Associations between perceived parent behaviours and middle school student fruit and vegetable consumption. J Nutr Educ Behav 36, 2-12.

13. De Bourdeaudhuij I \& Van Oost P (2000) Personal and family determinants of dietary behaviour in adolescents and their parents. Psychol Health 15, 751-770.

14. Lytle LA, Varnell S, Murray DM, Story M, Perry C, Birnbaum AS \& Kubik MY (2003) Predicting adolescents' intake of fruits and vegetables. J Nutr Educ Behav 35, 170-178.

15. Young EM \& Fors SW (2001) Factors related to the eating habits of students in grades 9-12. J Sch Health 71, 483-488.

16. Chao R (1994) Beyond parental control and authoritarian parenting style: understanding Chinese parenting through the cultural notion of training. Child Dev 65, 1111-1119.

17. Darling N \& Steinberg L (1993) Parenting style as context: an integrative model. Psychol Bull 113, 487-496.

18. Klepp KI, Pérez-Rodrigo C, De Bourdeaudhuij I et al. (2005) Promoting fruit and vegetable consumption among European schoolchildren: rationale, conceptualization and design of the Pro Children Project. Ann Nutr Metab 49, 212-220.

19. Wolf A, Yngve A, Elmadfa I et al. (2005) Fruit and vegetable intake of mothers of 11-year-old children in nine European countries: The Pro Children Cross-sectional Survey. Ann Nutr Metab 49, 246-254.

20. De Bourdeaudhuij I, Klepp KI, Due P, Rodrigo CP, de Almeida M, Wind M, Krølner R, Sandvik C \& Brug J (2005) Reliability of a questionnaire to measure personal, social and environmental correlates of fruit and vegetable intake in 10-11-year-old children in five European countries. Public Health Nutr 8, 189-200.

21. Wind M, Bobelijn K, De Bourdeaudhuij I, Klepp KI \& Brug $\mathrm{J}$ (2005) A qualitative exploration of determinants of fruit and vegetable intake among 10 - and 11-year-old schoolchildren in the low countries. Ann Nutr Metab 49, 228-235.

22. Haraldsdóttir J, Thórsdóttir I, De Almeida M, Maes L, Pérez Rodrigo C, Elmadfa I \& Frost Andersen L (2005) Validity and reproducibility of a precoded questionnaire to assess fruit and vegetable intake in European 11- to 12-year-old schoolchildren. Ann Nutr Metab 49, 221-227.

23. Sandvik C, De Bourdeaudhuij I, Due P et al. (2005) Personal, social and environmental factors regarding fruit and vegetable intake among schoolchildren in nine European countries. Ann Nutr Metab 49, 255-266.

24. Steinberg L, Elmen JD \& Mounts NS (1989) Authoritative parenting, psychosocial maturity, and academic success among adolescents. Child Dev 60, 1424-1436.

25. Lamborn SD, Mounts NS, Steinberg L \& Dornbusch SM (1991) Patterns of competence and adjustment among adolescents from authoritative, authoritarian, indulgent, and neglectful families. Child Dev 62, 1049-1065.

26. Sessa FM (1992) Family Structure, Parenting, and Adolescent Adjustment. Philadelphia, PA: Temple University.

27. De Bourdeaudhuij I, te Velde S, Brug J et al. (2007) Personal, social and environmental predictors of daily fruit and vegetable intake in 11-year-old children in nine European countries. Eur J Clin Nutr (Epublication ahead of print version). 
28. De Bourdeaudhuij I (1997) Family food rules and healthy eating in adolescents. J Health Psychol 2, 45-56.

29. Noller P (1994) Relationships with parents in adolescence: process and outcome. In Personal Relationships During Adolescence, pp. 37-77 [R Montemayor, G Adams and T Gullotta, editors]. London: Sage.
30. Wardle J, Carnell S \& Cooke L (2005) Parental control over feeding and children's fruit and vegetables intake: how are they related? J Am Diet Assoc 105, 227-232.

31. Crouter AC \& Booth A (2003) Children's Influence on Family Dynamics. Mahwah, NJ: Lawrence Erlbaum Associates. 